\title{
Battery Energy Storage System for Frequency Regulation of Isolated Island Microgrid
}

\author{
Cheng-Ting Hsu, ${ }^{*}$ Tsun-Jen Cheng, and Hung-Ming Huang \\ Department of Electrical Engineering, Southern Taiwan University of Science and Technology, \\ Yung-Kang 71005, Tainan, Taiwan
}

(Received September 6, 2020; accepted January 20, 2021)

Keywords: frequency sensor controller, battery energy storage system, solar photovoltaic plant

This paper presents the frequency enhancement of an isolated island microgrid by a battery energy storage system (BESS) with a frequency sensor controller (FSC). We selected the Chimei Island microgrid for our study. The total installation capacity of solar photovoltaic (SPV) plants is $410 \mathrm{kWp}$ with over $50 \%$ instantaneous penetration level. A BESS with the proposed FSC was installed to alleviate the impact of SPV power output variation on the microgrid. Load flow analysis and transient stability analysis were then executed with and without employing the BESS. The events of the largest SPV power plant tripping and all SPV output powers having a ramp rate (RR) of $70 \% / \mathrm{s}$ were selected for investigation via a simulation of transient stability. It was found that the frequency dropped below $57.3 \mathrm{~Hz}$ during these events without compensation by the BESS, which may result in the tripping of the load. However, the system frequency can be well maintained if the proposed FSC of the BESS is applied to support the operation of the microgrid.

\section{Introduction}

Increasing the supply of renewable energy can reduce greenhouse gas emissions and is considered a very important issue in achieving a sustainable environment. There are various forms of renewable energy resources, among which solar photovoltaic (SPV) energy has the most development potential owing to its decreasing cost and increasing performance. However, SPV power is highly intermittent and often non-dispatchable owing to the randomness of solar irradiance. ${ }^{(1,2)}$ Rapid fluctuation of the power output can be caused by passing clouds, which dramatically affect the system frequency. The generators or load may be tripped owing to excessive frequency variation, especially for weak power systems or small isolated island power systems when SPV plants have higher penetration.

Regarding the ramp rate (RR) of SPV power caused by short-term changes in the weather such as cloud passing, there are already many reports of practical operation. For example, a 1.2 MWp SPV power plant on La Ola Island once recorded an RR of $63 \% / \mathrm{min}$. $^{(3)}$ The National Renewable Energy Laboratory (NREL) once recorded an RR of $50 \% / \mathrm{s}$ on Oahu. ${ }^{(4)}$ Many utilities have a limit on the RR of no more than $10 \% / \mathrm{min}$ for SPV plants. This can be achieved by controlling the power electronic converter in the SPV plant. In addition, a battery energy *Corresponding author: e-mail: cthsu@stust.edu.tw https://doi.org/10.18494/SAM.2021.3162 
storage system (BESS) can also achieve similar RR control by active power compensation. An SPV plant generates electricity by harvesting solar energy. Also, energy storage is the capture of energy produced at one time for use when needed. A BESS is a technology developed for the storage and release of electric power by using various batteries. Thus, this paper is closely related to energy harvesters and energy storage applications. There are currently many BESSs operating in power grids. Typically, a BESS consists of two parts: a power conversion system (PCS) and a battery storage unit (BSU). The BESS can regulate its active and reactive powers quickly by properly controlling the PCS, and the RR of SPV power can be limited if a BESS is installed in an SPV plant. Furthermore, a BESS has many functions for ancillary services to help the operation of the power grid such as frequency regulation, ${ }^{(5-7)}$ reserve operation, voltage support, energy arbitrage, and backup power. ${ }^{(8-11)}$

There are many offshore islands in the world. The power supply of these islands is dominated by diesel generators, ${ }^{(12,13)}$ which contribute to greenhouse gas emissions and are vulnerable to increases in the cost of fuel. Renewable energy resources, such as wind power and SPV power, are very useful for solving both problems, although they are highly dependent on weather conditions. It is very important to determine the impact of a high penetration of SPV energy on isolated offshore islands. The Chimei Island microgrid was selected for study in this paper. The events of the largest SPV power plant tripping and all SPV power output variations having an RR of $70 \% / \mathrm{s}$ were investigated by transient stability analysis with an off-peak initial operating condition. ${ }^{(14)}$ To enhance system reliability, a BESS with a novel frequency sensor controller (FSC) and a speed governor system working together for frequency regulation can prevent unnecessary load shedding after the occurrence of disturbances.

\section{Microgrid on Chimei Island}

\subsection{Power system configuration}

Chimei Island is one of Taiwan's outlying islands. It has a total surface area of $6.99 \mathrm{~km}^{2}$ with about 3700 residents. Figure 1 shows a one-line diagram of the Chimei Island power system. There are four diesel engine generators on the island, each with a capacity of $1000 \mathrm{~kW}$. The voltage is boosted from 0.48 to $3.3 \mathrm{kV}$ through four step-up transformers with a capacity of $1500 \mathrm{kVA}$ each. The electricity is delivered to customers through three feeders, RB1, RB2, and RB3. Figures 2 and 3 show typical summer and winter day load curves of Chimei Island, respectively. The daily loads in summer and winter are about $1074-1530 \mathrm{~kW}$ and $714-1098 \mathrm{~kW}$, respectively. Therefore, loading of 1530 and $714 \mathrm{~kW}$ is selected for the peak and off-peak analysis, respectively. Two diesel generators are operated for the peak loading and one unit is operated for the off-peak loading. Furthermore, there are two small SPV plants with capacities of 25.3 and $30.36 \mathrm{kWp}$, and in the Green Energy Park of Chimei Island, there are two large SPV plants with capacities of 155 and $200 \mathrm{kWp}$. Also, a BESS with capacities of $250 \mathrm{~kW}$ (for converter) and $300 \mathrm{kWh}$ (for battery) is installed in the Green Energy Park to enhance the resiliency of the microgrid. There is a traditional low-frequency load shedding scheme on the island to prevent the collapse of the power system from an insufficient power supply. This scheme trips one of the three feeders when the operating frequency of the power supply decreases to below $57.3 \mathrm{~Hz}$. 


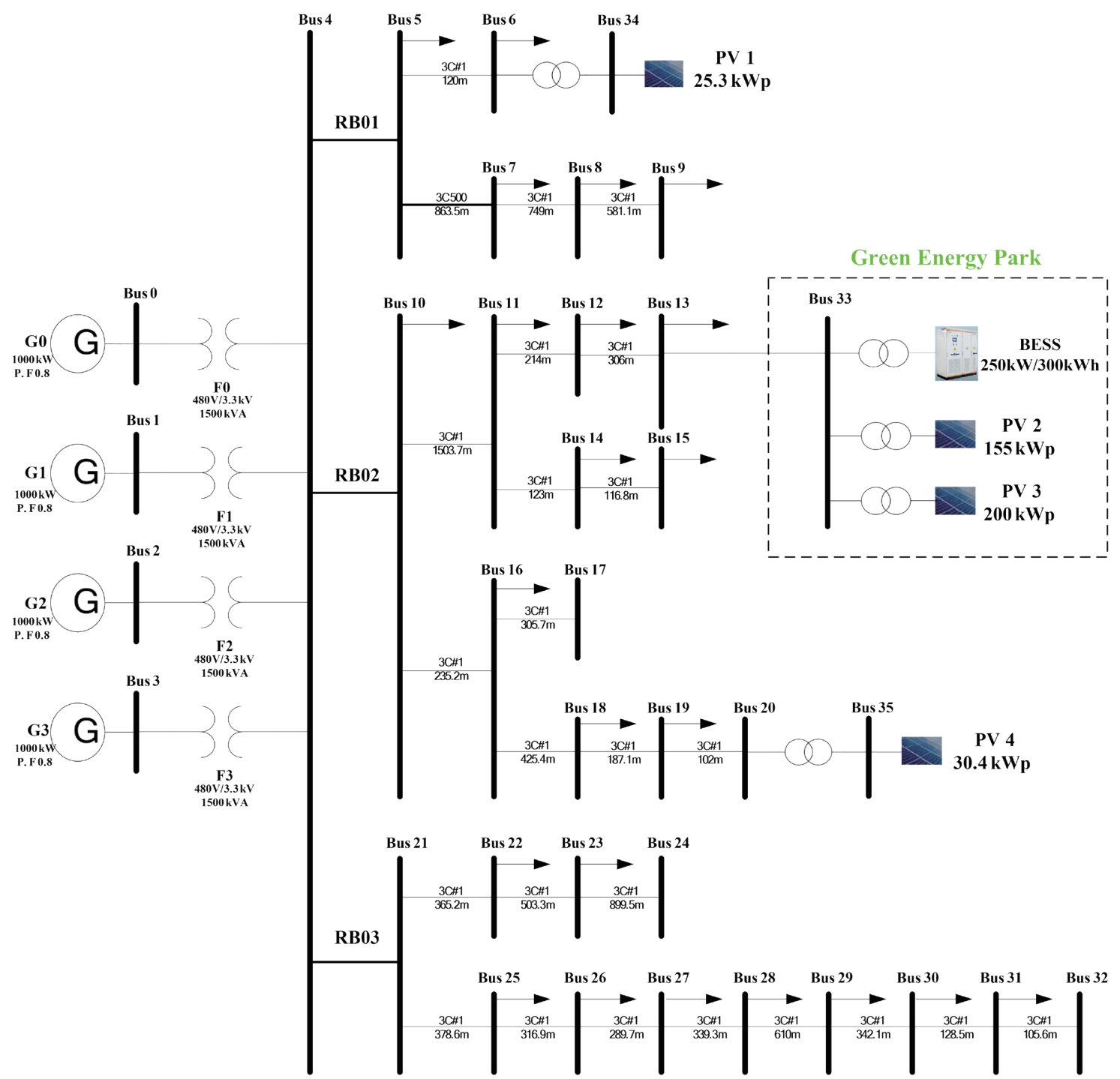

Fig. 1. (Color online) One-line diagram of Chimei Island power system.

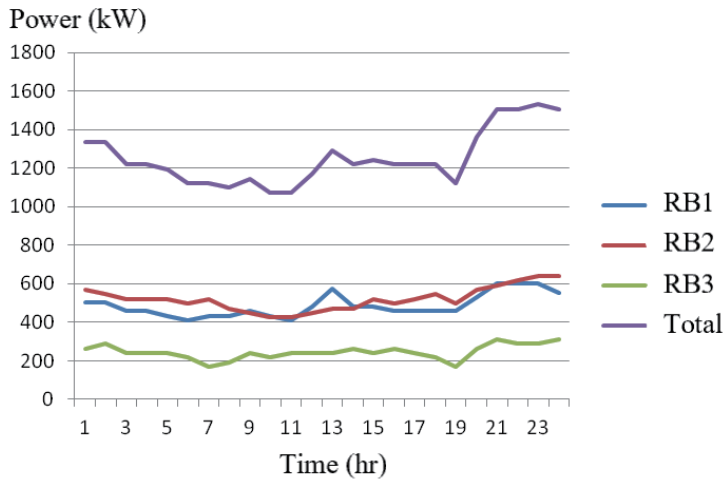

Fig. 2. (Color online) Typical daily load curve for summer day.

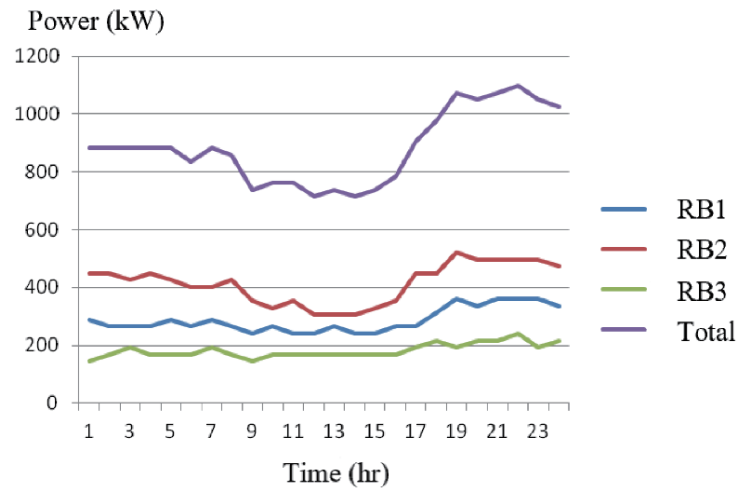

Fig. 3. (Color online) Typical daily load curve for winter day. 


\subsection{Modeling of diesel generator}

The minimum operating frequency of each diesel generator of the Chimei microgrid is $54 \mathrm{~Hz}$, and high-frequency tripping occurs at $66 \mathrm{~Hz}$. We performed transient stability analysis to investigate the impact of various disturbances on the microgrid. This required the accurate modeling of the generator including its speed governor system and the excitation system. The main function of the speed control system is to control the output mechanical power to maintain a stable system frequency. Figure 4 shows the mathematical model of the speed governor control system. ${ }^{(15)}$ All the generators are operated in a droop control mode and the corresponding parameters are given in Table 1.

\subsection{Output power RR of SPV plants}

The PV power output may vary significantly as a result of passing clouds. Also, the system frequency can fluctuate greatly, especially in low-power systems of remote islands. It is important to know the impact of SPV power output fluctuation on the frequency of the Chimei Island system. The RR of the SPV power output is evaluated as the change in the PV power output $\left(\Delta P_{p v}\right)$ divided by the interval $\Delta t$.

$$
R R_{p v}=\frac{\Delta P_{p v}}{\Delta t}
$$

Figure 5 shows the measured RR of the SPV plant in the Green Energy Park. The largest RR is $65 \% / 10$ min but the cumulative frequency for an RR of $10 \% / 10 \mathrm{~min}$ is almost $85 \%$.

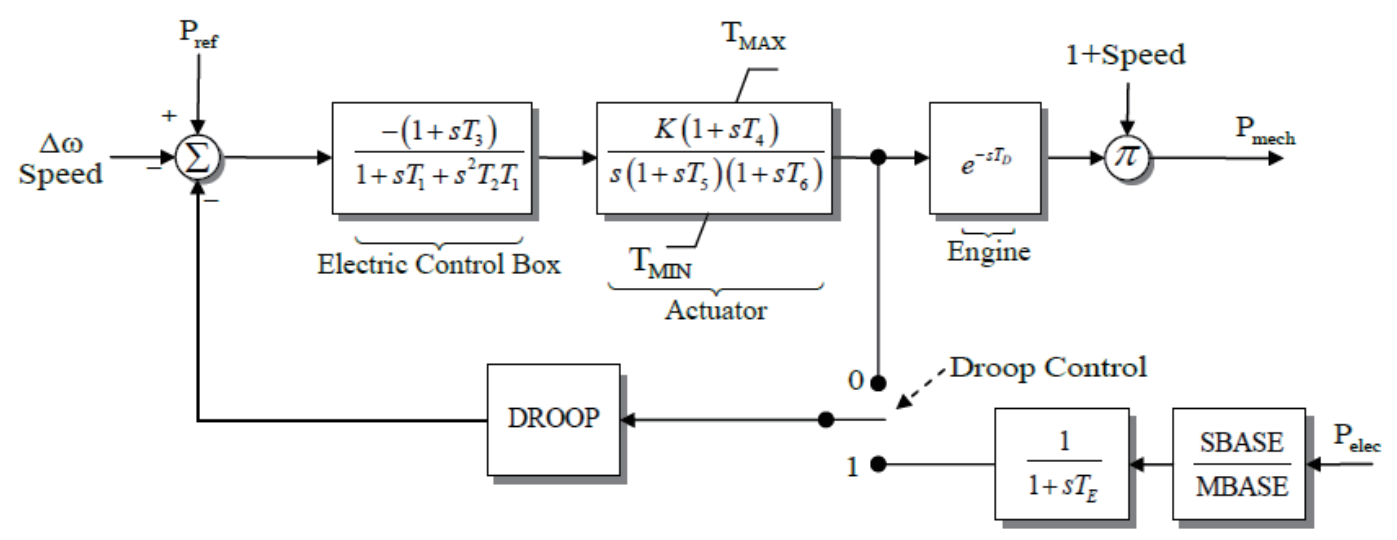

Fig. 4. Control block diagram of speed governor system.

Table 1

Parameters of the speed governor model.

\begin{tabular}{ccccccccccc}
\hline$T_{1}(\mathrm{~s})$ & $T_{2}(\mathrm{~s})$ & $T_{3}(\mathrm{~s})$ & $K$ (p.u.) & $T_{4}(\mathrm{~s})$ & $T_{5}(\mathrm{~s})$ & $T_{6}(\mathrm{~s})$ & $T_{D}(\mathrm{~s})$ & $T_{\max }$ (p.u.) & $T_{\min }$ (p.u.) & $T_{E}(\mathrm{~s})$ \\
\hline 0.022 & 0.02 & 0.1 & 3.5 & 0.1 & 0.039 & 0.009 & 0.05 & 1 & 0 & 0.39 \\
\hline
\end{tabular}




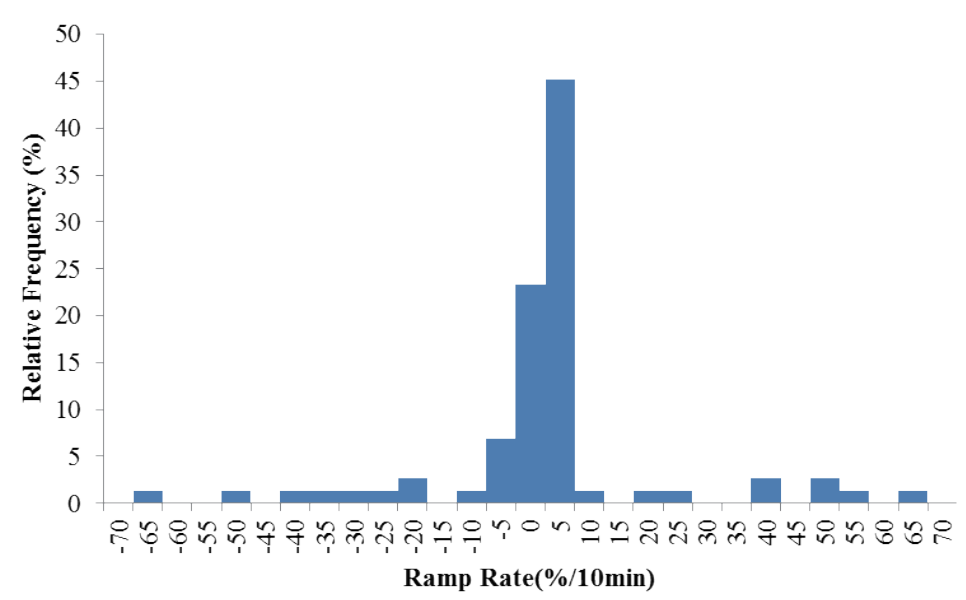

Fig. 5. (Color online) Power output RR of the SPV plant in the Green Energy Park.

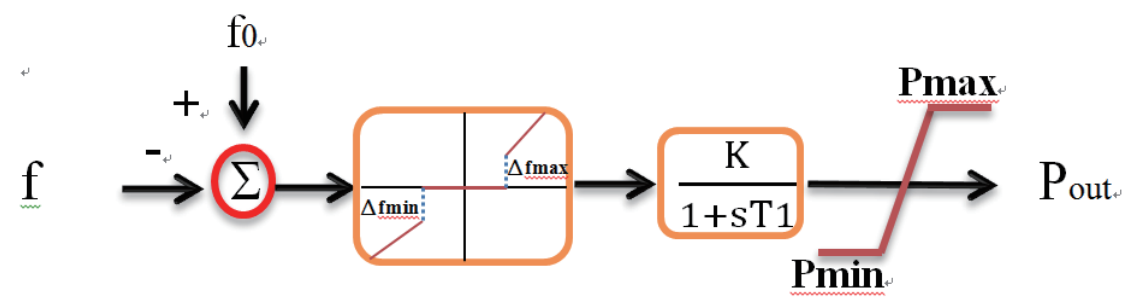

Fig. 6. (Color online) Control block diagram of BESS.

Table 2

Parameters of the BESS.

\begin{tabular}{cccc}
\hline$T_{1}(\mathrm{~s})$ & $K(\mathrm{pu})$ & $P_{\min }(\mathrm{MW})$ & $P_{\max }(\mathrm{MW})$ \\
\hline 0.065 & 100 & -0.25 & 0.25 \\
\hline
\end{tabular}

\subsection{FSC of BESS}

This paper presents an FSC of a BESS for system frequency support. By properly controlling the PCS, the active power output of a BESS can be regulated quickly. Therefore, the system frequency can be well maintained by using a BESS as an auxiliary service. A high-resolution frequency sensor is installed near the BESS site to detect the system frequency with a short time delay. The control block diagram of the BESS is shown in Fig. 6. The final power output $\left(P_{\text {out }}\right)$ of the BESS is regulated by taking the frequency as a feedback signal. A dead-band (DB) function is designed to prolong the battery life. In the figure, $K$ is the gain and $T_{1}$ is the time delay. Also, $P_{\min }$ and $P_{\max }$ are the minimum and maximum power output limits of the PCS, respectively. Table 2 lists the parameters of the proposed BESS controller. The DB settings for low and high frequencies are 59.5 and $60.2 \mathrm{~Hz}$, respectively. 


\section{Dynamic Responses for Events with SPV Output Power Variation}

We investigated the dynamic responses of the power system during two contingency events: the largest SPV plant tripping and all SPV plants having an RR of $70 \% / s$. The Cyme PSAF program was applied to execute steady-state and transient analyses. We selected the off-peak operating condition of about $714 \mathrm{~kW}$ loading for steady-state analysis. Meanwhile, the outputs of all four SPV plants on the island were assumed to operate with their maximum power generation of $411 \mathrm{~kW}$ with one generator in service to supply an active power of $310 \mathrm{~kW}$. To avoid under-frequency load shedding, a BESS with the proposed FSC is also considered in the computer simulation to verify its effectiveness for the frequency support of the microgrid.

\subsection{Largest SPV plant tripping event}

We first investigated the case of the PV power plant in the Green Energy Park tripping during full power generation of $355 \mathrm{~kW}$. Without the frequency regulation by the BESS, this event will trigger load shedding due to the low frequency and cause a power outage for some customers. Figure 7 shows the system frequency response. After the tripping of the SPV plant, the frequency decreases quickly to a minimum value of $53.5 \mathrm{~Hz}$ and then increases to a maximum value of $61.5 \mathrm{~Hz}$ for the system without compensation by the BESS. Figure 8 shows the generator output power response. The input mechanical power of the generator (red curve) increases from the initial value of $310 \mathrm{~kW}$ to a maximum value of $750 \mathrm{~kW}$ and finally stabilizes at $670 \mathrm{~kW}$. The green curve shows the electric power response.

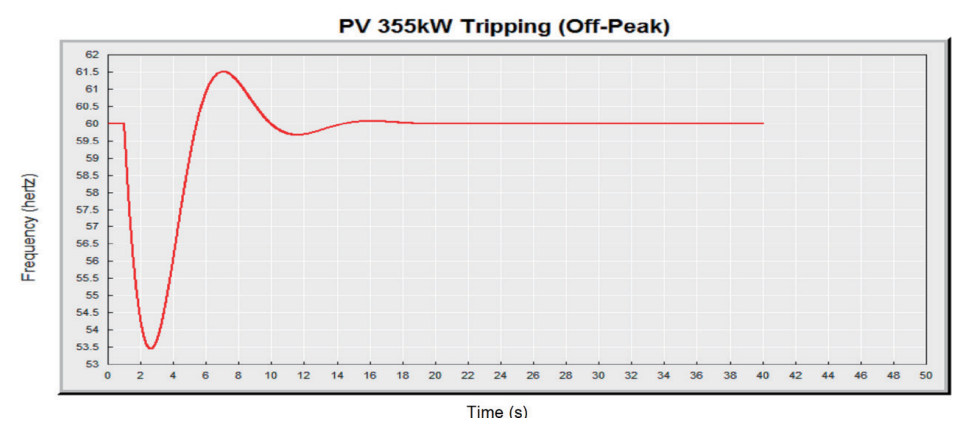

Fig. 7. (Color online) System frequency response due to SPV plant tripping w/o compensation by BESS.

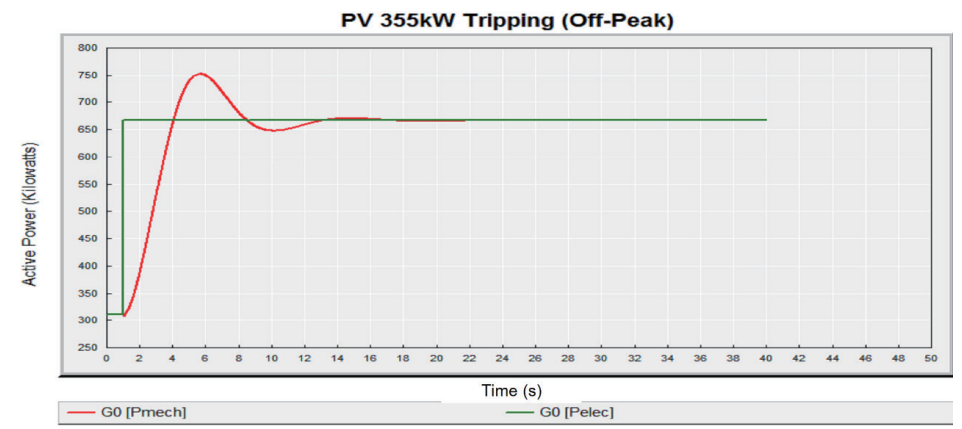

Fig. 8. (Color online) Generator power response due to SPV plant tripping w/o compensation by BESS. 
Next, the FSC of the BESS was applied to active power compensation. The DB of the FSC was set to 59.5 and $60.2 \mathrm{~Hz}$. Figure 9 shows the frequency response with the proposed BESS controller. The lowest frequency is $58.19 \mathrm{~Hz}$ and the highest frequency is $60.1 \mathrm{~Hz}$. The system frequency finally stabilizes at $60 \mathrm{~Hz}$, indicating isochronous governor control of the diesel generator. Figure 10 shows the response of the generator output power. With compensation by the BESS, the mechanical power of the generator increases gradually from 310 to $670 \mathrm{~kW}$. Figure 11 shows the output power response of the BESS. The active power almost immediately reaches a maximum value of $250 \mathrm{~kW}$ and then gradually drops to zero. The governor controller of the diesel generator can recover the system frequency with the auxiliary service of the BESS. Therefore, the minimum frequency can be improved effectively from 53.5 to $58.2 \mathrm{~Hz}$ while keeping the diesel generator in service without any customers experiencing a power outage.

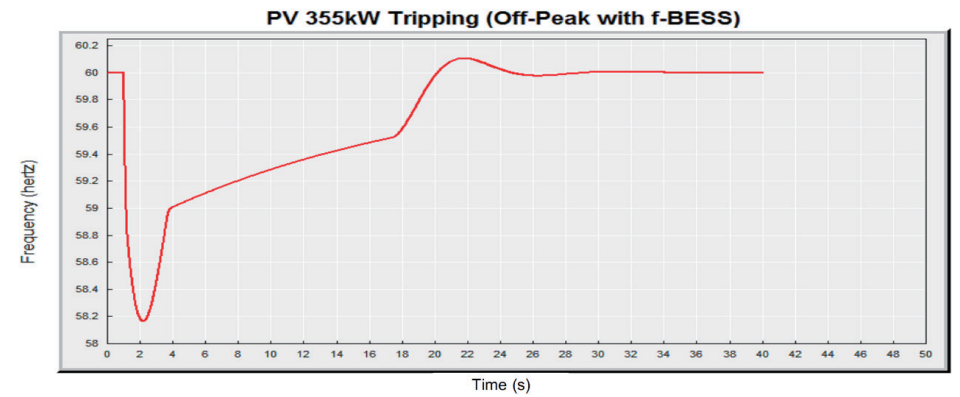

Fig. 9. (Color online) System frequency response due to SPV plant tripping with compensation by BESS.

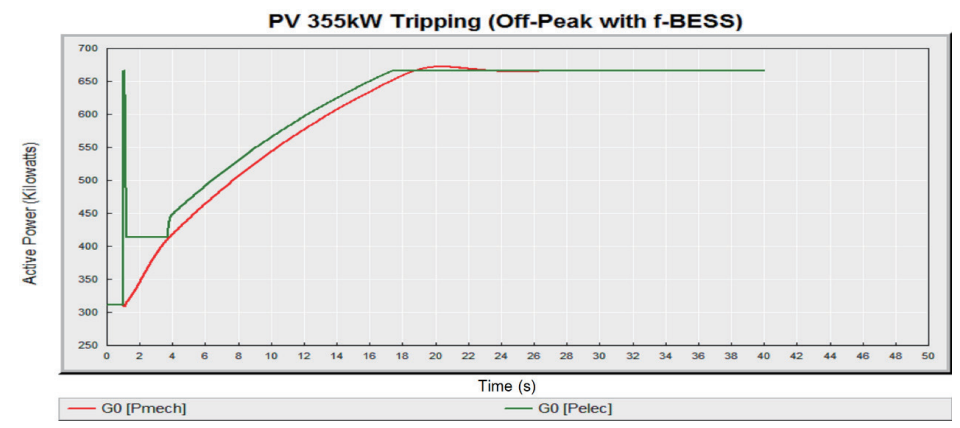

Fig. 10. (Color online) Generator power responses due to SPV plant tripping with compensation by BESS.

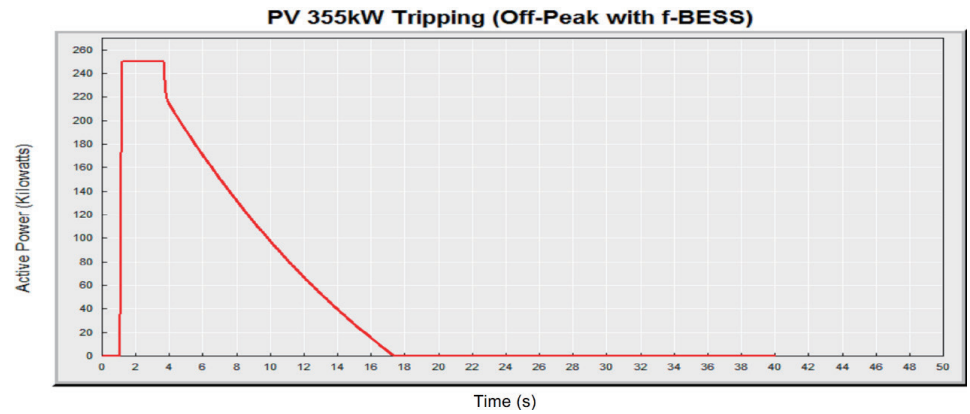

Fig. 11. (Color online) BESS output power response due to SPV plant tripping. 


\subsection{All SPV plants having RR of $70 \% / \mathrm{s}$}

In this scenario, all SPV plants on the island are assumed to have an RR of $70 \% / \mathrm{s}$ as shown by the green line in Fig. 12. Each SPV plant is operated at its rated power generation and its power output decreases at a rate of $70 \% / \mathrm{s}$ for $1 \mathrm{~s}$. After that, the power output is maintained for $1 \mathrm{~s}$. Finally, the power output increases at $70 \% / \mathrm{s}$ for $1 \mathrm{~s}$, then the initial power generation is maintained until the end of the simulation. Without the frequency regulation by the BESS, this event will trigger load shedding due to the low frequency. Figure 13 shows the system frequency response. After the active power variation of the SPV plants, the frequency decreases to a minimum of $55.5 \mathrm{~Hz}$ and then increases to a maximum of $63.3 \mathrm{~Hz}$. Figure 14 shows the generator output power response. The mechanical power of the generator increases from the

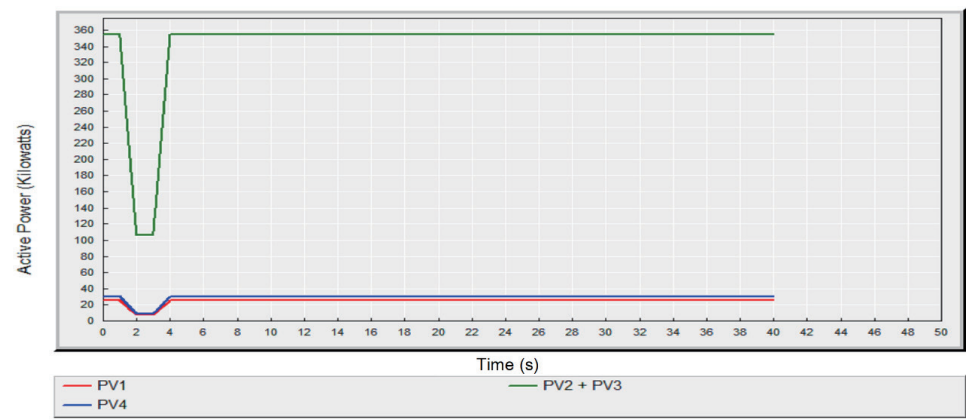

Fig. 12. (Color online) Output power variation curves of SPV plants.

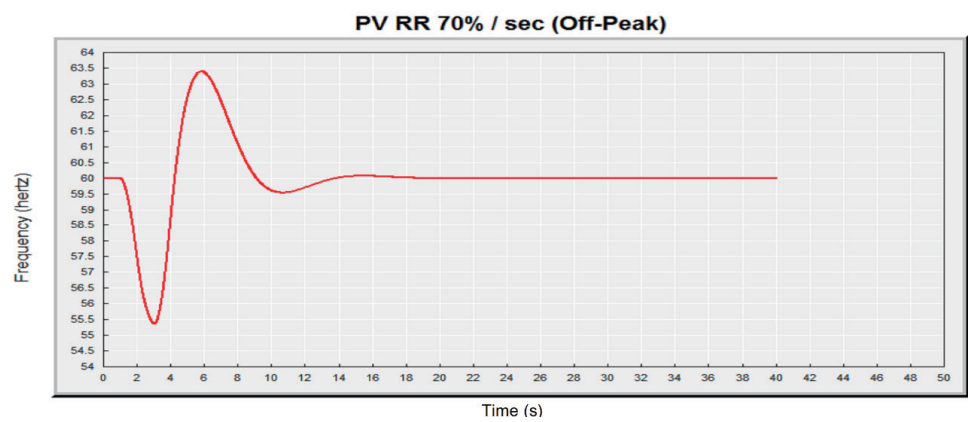

Fig. 13. (Color online) System frequency response due to variation of all SPV plants w/o compensation by BESS.

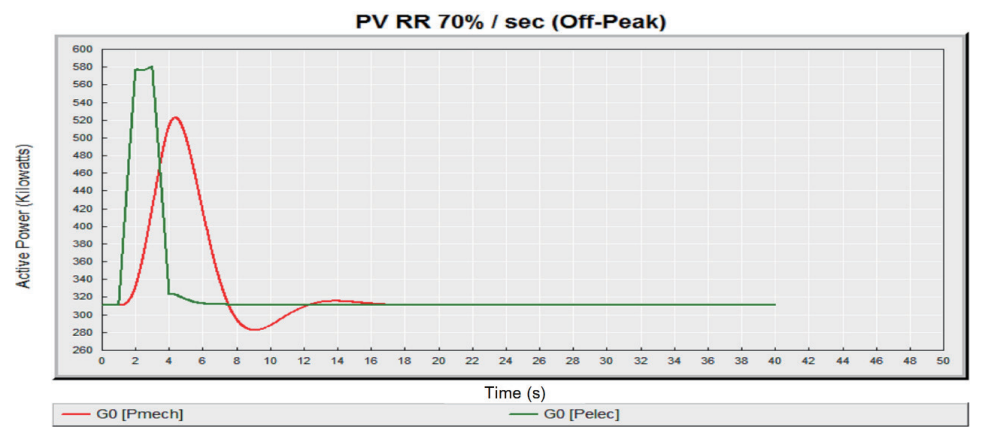

Fig. 14. (Color online) Generator power responses due to power variation of all SPV plants w/o compensation by BESS. 
initial value of $310 \mathrm{~kW}$ to the highest value of $522 \mathrm{~kW}$ and finally stabilizes at $310 \mathrm{~kW}$ as shown by the red curve. The lowest frequency of this event is higher than that of the previous SPV plant instantaneous tripping event because the governor controller of the generator has more time to react.

Then the proposed FSC of the BESS is applied to avoid the possibility of a total system blackout. Figure 15 shows the system frequency response with compensation by the BESS. The lowest frequency is $59 \mathrm{~Hz}$ and the highest frequency is $60.3 \mathrm{~Hz}$. The system frequency finally stabilizes at $60 \mathrm{~Hz}$. Figure 16 shows the response of the generator output power. The mechanical power of the generator increases from 310 to $370 \mathrm{~kW}$ and finally stabilizes at the initial value. Figure 17 shows the output power response of the BESS. Because the frequency exceeds the DB

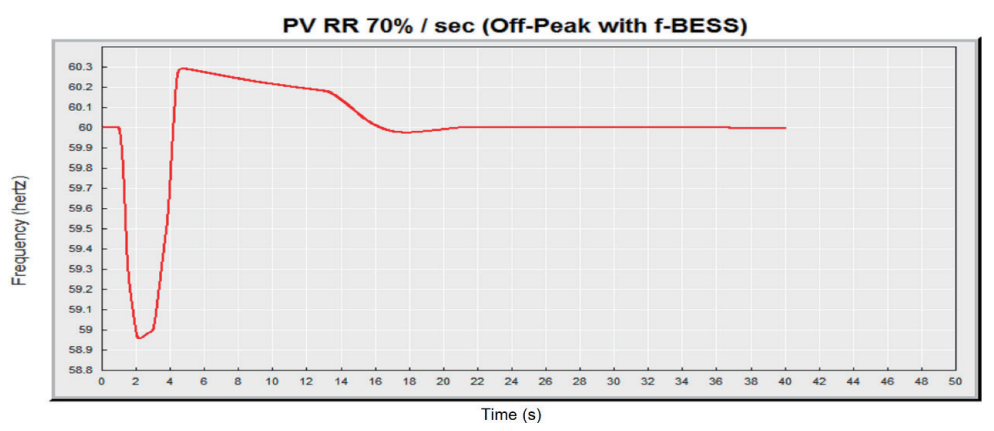

Fig. 15. (Color online) System frequency response due to power variation of all SPV plants with compensation by BESS.

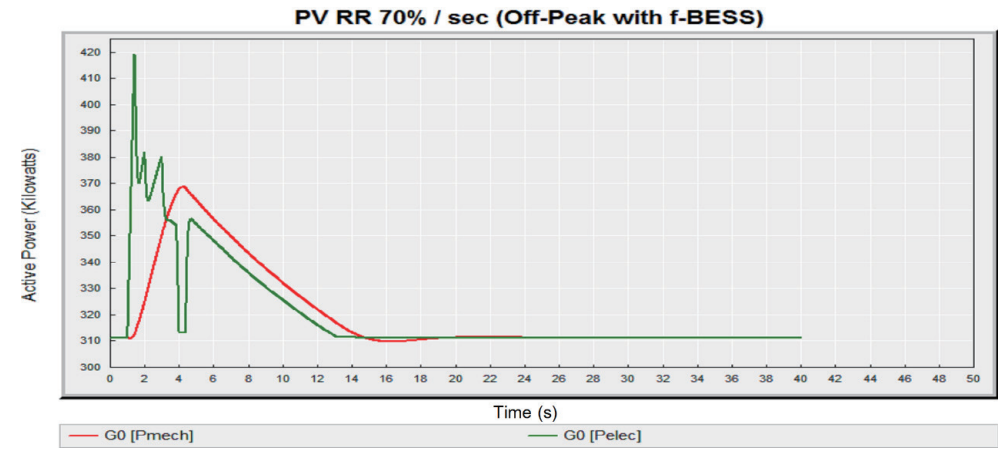

Fig. 16. (Color online) Generator power responses due to power variation of all SPV plants with compensation by BESS.

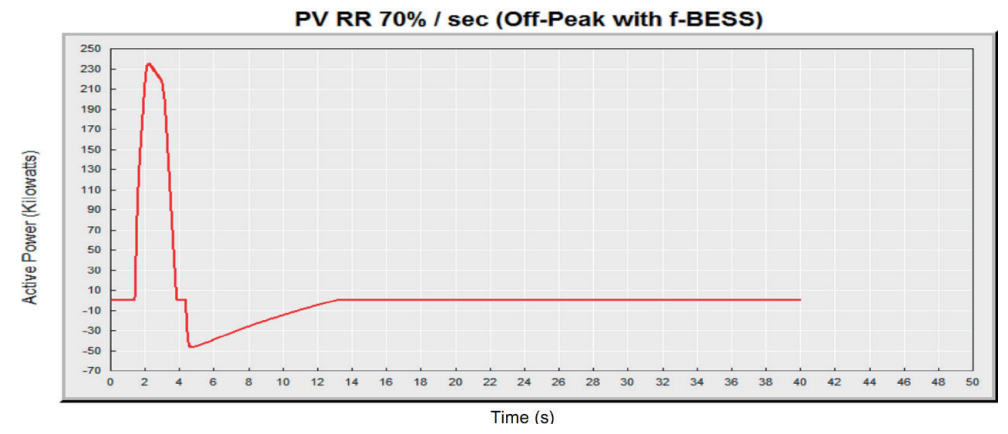

Fig. 17. (Color online) BESS output power response due to power variation of all SPV plants. 
setting, the output power of the BESS reaches a maximum value of $231 \mathrm{~kW}$ instantaneously and then decreases to zero. It is also observed that the BESS reaches a maximum power of $46.5 \mathrm{~kW}$ during the power recovery of the SPV plants. With the auxiliary service of the BESS, the lowest frequency can be improved from 55.5 to $59 \mathrm{~Hz}$ and the highest frequency can be damped from 63.3 to $60.3 \mathrm{~Hz}$.

\section{Results and Discussion}

In this study we considered the cases of the largest SPV plant tripping and all SPV plants having an RR of $70 \% / \mathrm{s}$ by computer simulation. It was found that the frequency varied in the range of 53.5-61.5 Hz for the largest SPV plant tripping event and in the range of 55.5-63.3 Hz for all SPV plants having an RR of $70 \% / \mathrm{s}$ without compensation by the BESS. Both events may result in the tripping of the load. However, the frequency can be maintained between 58.2 and $60.3 \mathrm{~Hz}$ for both events if the proposed FBC of the BESS is applied to support the operation of the diesel generator.

The novel FBC with the DB design of the BESS proposed in this paper has been installed in the Chimei Island microgrid for testing, The DB design is helpful for prolonging the battery life. A similar method of frequency regulation has already been presented as an example for demonstration: the pilot grid-scale BESS project of Electricity Generating Authority of Thailand (EGAT) ${ }^{(5)}$ However, there was no control block diagram in Ref. 5.

\section{Conclusions}

In this paper, an isolated island microgrid with a high penetration of SPV power generation was studied. We proposed a novel FSC for a BESS and verified its effectiveness in frequency regulation. The FSC was designed with a DB to avoid excess sensitivity and to prolong the battery life. Two events involving SPV plant output power variations were selected for examination by transient stability simulation. Without compensation by the BESS, the frequency dropped too low in both events, triggering load shedding protection. However, the frequency can be maintained above $57.3 \mathrm{~Hz}$ and load shedding will not be activated if the proposed FSC of the BESS is applied to support the operation of the microgrid.

\section{Acknowledgments}

This work was supported by the Ministry of Science and Technology of Taiwan (MOST 109-3116-F-042A-008-CC2).

\section{References}

1 R. O. Bawazir and N. S. Cetin: Energy Rep. 6 (2020) 173. https://doi.org/10.1016/j.egyr.2019.12.010

2 M. J. E. Alam, K. M. Muttaqi, and D. Sutanto: IEEE Trans. Energy Convers. 29 (2014) 507. https://doi. org/10.1109/TEC.2014.2304951

3 J. Johnson, B. Schenkman, A. Ellis, J. Quiroz, and C. Lenox: Proc. 2012 IEEE 38th Photovoltaic Specialists Conf. (PVSC) PART 2 1-6. https://doi.org/10.1109/PVSC-Vol2.2012.6656701 
4 NREL Measurement and Instrumentation Data Center (MIDC): http://www.nrel.gov/midc/oahu_archive/ (accessed January 2021).

5 N. Chatrung: Proc. 2019 IEEE PES GTD Grand Int. Conf. Exposition Asia (GTD Asia) 589-593. https://doi. org/10.1109/GTDAsia.2019.8715953

6 M. C. Such and G. Y. Masada: Proc. 2017 IEEE Power \& Energy Society General Meeting (2017) 1-5. https:// doi.org/10.1109/PESGM.2017.8274644

7 T. T. Ku, and C. S. Li: Proc. 2020 IEEE/IAS 56th Industrial and Commercial Power Systems Technical Conference (I\&CPS, 2020) 1-8. https://doi.org/10.1109/ICPS48389.2020.9176762

8 G. V. B. Kumar, G. Anil Kumar, S. Eswararao, and D. Gehlot: Proc. 2018 Int. Conf. Computation of Power, Energy, Information and Communication (ICCPEIC, 2018) 1-5. https://doi.org/10.1109/ICCPEIC.2018.8525173

9 EPRI Electric Energy Storage Technology Options: https://www.epri.com/research/ products/000000000001022261 (accessed January 2021).

10 X. Li, and D. Zhang: Proc. 2018 Int. Conf. Advanced Mechatronic Systems (2018) 1-5. https://doi.org/10.1109/ ICAMechS.2018.8506868

11 C. T. Hsu, T. J. Cheng, and H. M. Huang: Sens. Mater. 32 (2020) 1689. https://doi.org/10.18494/SAM.2020.2693

12 C. T. Hsu, T. J. Cheng, H. M. Huang, Y. D. Lee, Y. R. Chang, and J. L. Jiang: Micro. Rel. 92 (2019) 42. https:// doi.org/10.1016/j.microrel.2018.11.011

13 C. C. Yeh, C. S. Chen, T. T. Ku, C. H. Lin, C. T. Hsu, Y. R. Chang, and Y. D. Lee: IEEE Trans. Ind. Appl. 53 (2017) 947. https://doi.org/10.1109/TIA.2016.2627518

14 V. Salehi, and B. Radibratovic: Proc. IEEE PES General Meeting (IEEE, 2014) 1-5. https://doi.org/10.1109/ PESGM.2014.6938985

15 IEEE Working Group: IEEE Std 421.5-2016 (2016). https://doi.org/10.1109/IEEESTD.2016.7553421

\section{About the Authors}

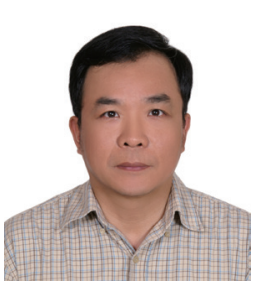

Cheng-Ting Hsu was born in Taiwan in 1963. He received his Ph.D. degree in electrical engineering from National Sun Yat-Sen University, Taiwan, in 1995. He is currently a professor of electrical engineering at Southern Taiwan University of Science and Technology, Taiwan. His major areas of interest are computer control of power systems, smart grids, and renewable energy.

(cthsu@stust.edu.tw)

Tsun-Jen Cheng was born in Taiwan in 1958. He received his B.S.E.E. degree from National Chiao Tung University, Taiwan, and his M.S.E.E. degree from Arizona State University, USA. He is currently a lecturer at Southern Taiwan University of Science and Technology, Taiwan. His major areas of interest are control systems and microprocessor applications. (chengtj@stust.edu.tw)

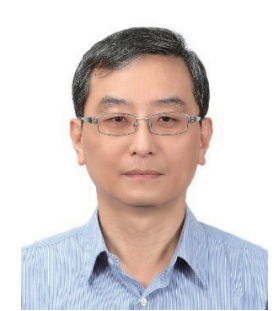

Hung-Ming Huang was born in Taiwan in 1961. He received his Ph.D. degree in electrical engineering from National Taiwan University, Taiwan, in 1994. $\mathrm{He}$ is currently an assistant professor of electrical engineering at Southern Taiwan University of Science and Technology, Taiwan. His major areas of interest are power system analysis and microprocessor applications.

(hhm3333@stust.edu.tw) 